\title{
Corruption, Tax Evasion and Social Values
}

\author{
Anastasia Litina \\ Theodore Palivos* \\ University of Luxembourg \\ Athens University of Economics and Business
}

June 26, 2014

\begin{abstract}
We provide empirical support and a theoretical explanation for the vicious circle of political corruption and tax evasion in which countries often fall into. We address this issue in the context of a model with two distinct groups of agents: citizens and politicians. Citizens decide the fraction of their income for which they evade taxes. Politicians decide the fraction of the public budget that they peculate. We show that multiple self-fulfilling equilibria with different levels of corruption can emerge based on the existence of strategic complementarities, indicating that corruption may corrupt. Furthermore, we find that standard deterrence policies cannot eliminate multiplicity. Instead, policies that impose a strong moral cost on tax evaders and corrupt politicians can lead to a unique equilibrium.
\end{abstract}

JEL Classification: D73; E62; H26

Keywords: Corruption, Tax Evasion, Multiple Equilibria, Stigma

${ }^{*}$ Corresponding Author: Department of Economics, Athens University of Economics and Business, 76 Patission Str., GR104 34, Athens, Greece. E-mail: tpalivos@aueb.gr, Tel: +30210 8203346. 


\section{Introduction}

Corruption and the misuse of government revenue often provide the moral justification for tax evasion. Indeed, corruption and tax evasion are often highly persistent and correlated. For example, there seems to be little disagreement to the claim that the current Greek economic tragedy is a play that involves both of these issues. In fact, as two Greek economists have written in a recent article:

We contend that a crucial factor in this respect, and which has been steadily eroding the foundations of Greek society and will impact on the resolution of the current fiscal crisis, is the interdependence between the tax burden, public good provision, tax compliance ... The rise of budget deficits during the last three decades reflects in addition to outright corruption, the increasing inability of the public sector to deliver on the public goods and services that the higher-taxed citizens ... have every right to expect in return. This has created a further "legitimization" of tax evasion ... (Moutos and Tsitsikas 2010, p. 173)

Political corruption, evidenced by a series of scandals, together with massive tax evasion and low quality of public services have been the case in Greece for at least the last three decades. This extensive corruption has resulted in a decline in social capital, a mutual distrust between citizens and the government and a social legitimization of tax evasion and bribery. ${ }^{1}$ We view the situation that existed in Greece prior to the onset of the current crisis a typical example of what we analyze in the rest of the paper.

The aim of this paper is to focus on the role of norms in fostering corruption and tax evasion. We argue that various manifestations of corruption may coexist and reinforce each other. The corrupt behavior of one group may become a strategic complement for another. In such a context, whenever agents expect other agents to be corrupt, they always find it optimal to be corrupt as well. An example of such a vicious circle is that

\footnotetext{
${ }^{1}$ Currently, the country ranks 80th among 177 countries, with a Corruption Perception Index (CPI) in 2013 of 4.0. Moreover, according to the 4 th wave of the World Values Survey: a) $37.1 \%$ of the respondents agree with the statement "It is never justifiable to cheat on taxes"; b) $64.4 \%$ agree with the statement "It is never justifiable accepting a bribe"; c) $23.7 \%$ agree with the statement "Most people can be trusted"; d) $85.7 \%$ have "no confidence in civil services"; These numbers differ substantially from those in other countries, even with a similar CPI, e.g., India and China. For further details, see Litina and Palivos (2013).
} 
of widespread political corruption and high tax evasion, which will be the focus of the paper.

Analytically, we construct a model economy that comprises two distinct groups of agents: private citizens and politicians. Citizens decide how much of their income to report to the tax authorities, taking into account the exogenously given probability of inspection and the size of the delinquent tax penalty. A certain fraction of tax revenue is supposed to be spent for the provision of a public good. Politicians, on the other hand, have the opportunity to peculate a certain fraction of the public funds that are earmarked for the public good. Crucially, each agent cares not only about her own consumption but also about the quantity/quality of the public good.

In such a context strategic complementarities may arise, leading to multiple selffulfilling equilibria: a "good" ("bad") equilibrium with low (high) corruption, low (high) percentage of tax evasion and a high (low) share of output spent on the public good. The existence of multiple equilibria can help us understand why countries with similar background are characterized by different levels of corruption and tax evasion. It can also provide some insights as to why these two phenomena are so difficult to eradicate.

We then examine the use of standard deterrence policies not only as a means to fight corruption and tax evasion, but also as a policy device to select an equilibrium in general. We show that in the presence of multiple equilibria driven by strategic complementarities in corrupt activities, standard policies, such as fines, are not very effective. The reason is that whereas standard deterrence policies may increase the cost of tax evasion, they are unsuccessful in terminating the strategic complementarity between groups.

Next we modify the model to study alternative compliance schemes. In particular, we assume a social stigma cost associated with being involved in corrupt activities, i.e., individuals who commit unlawful actions and get caught are stigmatized by the society. ${ }^{2}$ If this social cost is sufficiently high, then the multiplicity of equilibria is eliminated and the economy converges to a unique equilibrium. The intuition behind the success of social policies lies in that they effectively address the strategic complementarity aspect of corruption.

Our analysis contributes to different strands of the literature. First, it provides a theoretical framework that can account for the following empirical facts. Existing evidence suggests that there is a positive correlation between corruption and tax evasion. The two

\footnotetext{
${ }^{2}$ There is an extensive literature that assumes the presence of a social stigma cost; see Section 5 below.
} 
of them often coexist and reinforce each other (Amudnsen 1999; Barreto and Alm 2003). Moreover, there seems to be a negative correlation between any of these two phenomena and spending on publicly provided goods, such as education and health (see, e.g., Mauro 1995, 1998; Tanzi and Davoodi 1997). ${ }^{3}$

Second, it contributes to the literature emphasizing the importance of social cost policies. Our analysis suggests that social policies are particularly useful in the presence of multiple equilibria as an equilibrium selection mechanism, since they can give an end to strategic complementarity in corrupt activities. Examining the role of moral costs in the context of tax evasion and corruption is motivated by the following empirical facts. Graetz and Wilde (1985) and Skinner and Slemrod (1985) have empirically estimated the compliance rates of various countries and have found them significantly higher than expected, taking into account low auditing probabilities and fines. Also, taking into account that in most countries audits are not very extensive, e.g., the average audit rate for individual tax returns in the US is less that 1\% (McCaffery and Slemrod, 2004), the rate of tax compliance is estimated to be rather high. ${ }^{4}$ Most models cannot account for these high rates unless they introduce some form of moral considerations (e.g., Sandmo 2005; Alm and Torgler 2011). Moreover, a number of experimental studies have indicated that some people never evade or they evade less than expected (Alm et al. 1992). Another strand of the related literature has highlighted the fact that countries with similar fiscal systems and deterrence policies experience different levels of compliance. Many researchers have argued that, to account for these observations, one must introduce some form of moral costs related to tax evasion (see Lewis 1979, for the United Kingdom; Alm et al. 1995, for the US; Alm and Torgler 2006, for the US and Europe). Among the main conclusions are that non-evading individuals are the ones that view tax evasion as immoral as well as that individuals who have friends that evade taxes tend to evade more themselves (see Alm et al. 2013). In addition, the literature finds that in societies with a stronger feeling of social cohesion, tax compliance is higher as well as that social norms are a crucial determinant for tax evasion.

\footnotetext{
${ }^{3}$ Mauro (1995) reports that a decrease in corruption by 1.5 units in the BI corruption index could increase spending on education up to $0.6 \%$.

${ }^{4}$ Rates of tax evasion in most western developed countries are estimated around $5 \%-25 \%$ of potential tax revenue (Pyle, 1989; Thomas, 1992). In developing countries, tax evasion rates are higher (Tanzi and Shome, 1994).
} 
To uncover empirically the nexus between political corruption and tax evasion, we use individual survey data from the World Values Survey and the General Social Survey. More specifically, the empirical section of the paper is developed in two parts. The first part of the analysis establishes a positive correlation between individual attitudes on whether or not it is justifiable to cheat on taxes and the level of perceived political corruption. Analytically, our empirical findings suggest that the higher the level of political corruption (as perceived by citizens) the more justifiable they find it to cheat on taxes. Thus, in line with the theory, our empirical findings confirm the presence of an interaction between the attitudes of the two groups. Causality runs both ways and therefore this section does not yet address the issue of endogeneity; it just highlights the interaction between the two groups. The analysis controls for a number of individual characteristics as well as for country and World Values Survey round fixed effects.

In the second part of the analysis, we seek to mitigate the issue of endogeneity and to make sure that the suggested correlation does not pick up the effect of any unobservables. Thus, we adopt the so-called epidemiological approach and extend our analysis to a sample of migrants who currently reside in the US. ${ }^{5}$ Our findings suggest that higher (mean) levels of perceived political corruption in the origin country have a persistent effect on individual attitudes of migrants towards tax evasion in the US (the host country). We carefully select our sample to include only second and third generation migrants in order to address concerns about selective migration and endogeneity. Since all our migrants were born in the US and are faced with the same sociopolitical environment, we have netted out the potential effect of the residence country. Moreover, since these migrants have no systematic interaction with the country of origin of their parents, other than their parents' culture, we can safely argue that the issue of endogeneity has been effectively suppressed (see Fernandez and Fogli 2009). Reassuringly, our results further confirm the interaction between attitudes towards political corruption and tax evasion, an interaction that is not driven by unobservables or reverse causality. ${ }^{6}$

\footnotetext{
${ }^{5}$ The same approach is applied, for example, in Guiso et al. (2006) for the role of culture, Giuliano (2007) for living arrangements in Western Europe, Alesina and Giuliano (2010) for the role of family in influencing economic behavior and attitudes, Fernandez and Fogli (2009) for fertility and Bentzen (2013) for religiousness of second generation migrants.

${ }^{6}$ The persistent effect of preferences at the home country on migrants' attitudes has also been established in the context of preferences for redistribution and environmental preferences (Luttmer and Singhal, 2011; Litina et al., 2014).
} 
The remainder of the paper is organized as follows. Section 2 introduces the benchmark model that poses the problem and describes the emergence of multiple equilibria and the effects of corruption in a society without deterrence policies. Section 3 introduces standard enforcement policies and highlights their limited effectiveness in the fight against corruption. Section 4 describes the functioning of a moral-based society and demonstrates why imposing an ethical cost on corrupt activities effectively deters corruption. In Section 5, we presents our empirical findings. Finally, Section 6 summarizes the results and draws conclusions.

\section{The Benchmark Model}

\subsection{The economy}

Consider an overlapping generations economy where individuals live for two periods. ${ }^{7}$ The population size remains constant. In the first period of life, all agents are identical. They enter the public education system and acquire human capital according to the learning technology

$$
h_{t+1}=v H_{t}+A E_{t},
$$

where $t=0,1,2 \ldots$ indexes time and $h_{t+1}$ denotes the level of human capital of an individual born in period $t$; this level of human capital is formed in period $t$, but it is put to use in period $t+1$. Moreover, $H_{t}$ is the average stock of human capital at time $t$ and $E_{t}$ denotes public spending on education. ${ }^{8}$ The human capital accumulation process described by equation (1) shares common features with several papers in the literature; see, among others, De Gregorio and Kim (2000), Ceroni (2001), Palivos and Varvarigos (2010, 2013). Accordingly, a young agent, who was born in period $t$, can pick up a fraction $v \in[0,1]$ of the existing (average) level of human capital $H_{t}$ without any cost, simply by observing what the previous generation does. ${ }^{9}$ The enhancement of an agent's human capital even further is possible only with the use of resources. In this paper, we

\footnotetext{
${ }^{7}$ For the sake of concreteness, we choose the publicly provided good to be education, which is usually financed by one generation and consumed by another. This is the main reason that we use an overlapping generations economy.

${ }^{8}$ Given that the population size is constant, it is inconsequential if $E$ denotes the total spending on education, the spending per student or some function of it. Similarly, $H$ in (1) could denote the total instead of the average level of human capital. Whereas these issues can be important in a different context, in our framework they bear little significance.

${ }^{9}$ The term $1-v$ can be taken to capture the depreciation rate of the stock of knowledge.
} 
consider only public education and hence the level of public spending enters the learning technology. The parameter $A>0$ measures the efficiency of the public education system. Finally, the specific functional form in equation (1) is used purely for convenience; it allows us to derive analytical expressions.

For simplicity, we assume that agents do not consume in the first period, or that their consumption is included in the consumption of their parents. Instead, agents derive utility from consumption in the second period of their life and from their offspring's level of human capital. The latter is meant to capture the idea that parents care about their offspring's future prospects and social status (both being enhanced through more advanced knowledge and/or increased income). Formally, individuals born in period $t-1$ wish to maximize the following utility function:

$$
u_{t-1}=c_{t}\left(h_{t+1}\right)^{\beta}, \quad \beta \in(0,1],
$$

where $c_{t}$ and $h_{t+1}$ stand for the levels of consumption when old and offspring's human capital, respectively. The parameter $\beta$ measures the strength of the altruistic motive. ${ }^{10}$ Note that the presence of the offspring's human capital level in parental utility function results in an agent's vested interest in public education.

At the end of a cohort's first period of life, a small number of agents emerge via a random process and become politicians. This group forms the central government, while the rest of the population remain private citizens. For simplicity, we assume that the number of politicians is equal to one. The number of private citizens, on the other hand, is $N$. When necessary, we use the subscripts $c$ and $p$ to denote variables that are related to citizens and the politician, respectively.

\section{Citizens}

In the second period of their life, private citizens assume production of a single consumption good. Using the appropriate normalization of units, we assume that the wage rate per unit of human capital is equal to unity and hence each old citizen's income is equal to the (common) level of human capital $h_{t} \cdot{ }^{11}$ This income is taxed at the rate $\tau$, which is assumed to be exogenous and time invariant. Nevertheless, citizens have the

\footnotetext{
${ }^{10}$ Variations of this utility function abound in the literature; see, for example, Glomm (1997), Ceroni (2001) and Palivos and Varvarigos (2010, 2013).

${ }^{11}$ Since all agents have the same level of human capital, we omit the subscript $i=c, p$ from the level of human capital $h_{t}$.
} 
opportunity to tax evade. In particular, we let $z_{t}$ denote the fraction of their income that they declare to the tax authorities, leading to an amount $\tau z_{t} h_{t}$ that is paid as income tax.

Naturally, when it comes to engaging in corrupt activities that inflict some form of punishment, it is expected that involved agents try to conceal their corrupt activities and the effort to conceal these activities implies an inherent cost. In the case of tax evasion, the involved cost may imply the cost to hire a practitioner, the cost of bribing the tax inspector, etc. The idea of transaction costs is not new in the literature. Cowell (1990) and Chen (2003), among others, assume that tax evasion involves a transaction cost, which, in general, increases along with the extent of tax evasion. Critically in our model we make the additional assumption that the transaction cost involved to conceal any illegal activities relates negatively to the expected overall level of corruption as perceived by the actions of the reference group, namely the politicians in our model. ${ }^{12}$ The idea of this assumption is to capture the fact that in very corrupt societies, where one could claim that tax evasion has in some sense been "legitimized," the effort needed to conceal corruption is reduced. Put differently, in corrupt societies, where bribery is widespread among politicians, the cost of evading taxes is lower.

Following the literature, and in particular Cowell (1990) and Chen (2003), we assume that tax evasion involves a transaction cost, which, in general, increases along with the extent of tax evasion, the level of income and the level of honesty of the politician. This cost can be perceived as an effort to conceal tax evasion, e.g., hiring a tax practitioner (Andreoni et al. 1998). More specifically, we assume that the per unit cost of tax evasion $(S)$ is $S=s\left(1-z_{t}\right) \mu_{t}$, where $s>0$ is a fixed parameter; $1-z$ is the degree of tax evasion; and, as explained in detail below, $\mu$ denotes the proportion of the education budget that is actually spent on education; that is, $1-\mu_{t}$ is the percentage of the education budget that is embezzled by the politician; hence, $\mu$ is a measure of how honest the politician is. The total transaction cost of tax evasion for each agent is then $S\left(1-z_{t}\right) h_{t}=s\left(1-z_{t}\right)^{2} \mu_{t} h_{t}$, which is analogous to the expressions found in the literature (see, for example, Chen 2003, pp. 384-385). Finally, in the benchmark model there are no penalties imposed on tax evaders. In other words, by paying the transaction cost, agents are able to conceal tax evasion fully. ${ }^{13}$

\footnotetext{
${ }^{12}$ In a representative agent model, Chen (2003) assumes that the smaller the overall level of corruption in the economy, the cheaper it is to evade taxes.

${ }^{13}$ More realistic versions of the model, where fines are imposed on tax evaders, are analyzed in the next section and in Appendix A.2.
} 


\section{Politician}

The politician receives a payment (net of taxes) from the government budget. In addition, he has the option to embezzle public funds. ${ }^{14}$ More specifically, he decides what fraction $1-\mu_{t}$ of tax revenue to embezzle. In the benchmark model, there is no fine imposed on the politician, even after he has been found guilty of embezzlement. A more realistic version is examined in the next section. Still, given the politician's vested interest in public education, $1-\mu$ may not be equal to unity (see below).

\section{Spending on Education}

The total tax revenue collected within a period $t$ is $R_{t}=N \overline{z_{t}} \tau H_{t}$, where $\bar{z}$ denotes the average value of $z$. A constant fraction $1-\phi$ of this revenue is earmarked for public sector wages; that is, the politician's net income is equal to $(1-\phi) R_{t}=(1-\phi) N \overline{z_{t}} \tau H_{t}$. The remaining amount $\phi N \overline{z_{t}} \tau H_{t}$ is to be spent on public education. Nevertheless, the politician peculates a fraction $1-\mu_{t}$ of this sum. Hence, the actual amount spent on education $E_{t}$ is

$$
E_{t}=\mu_{t} \phi N \tau \overline{z_{t}} H_{t}
$$

Evidently, individual optimization decisions regarding $z_{t}$ and $\mu_{t}$ affect total spending on education and consequently the human capital of generation $t$.

\subsection{Individual optimization}

\section{Citizens}

As mentioned above, in period $t$ each citizen's gross income is $h_{t}$. A fraction $z_{t}$ of this is declared to the tax authorities and an amount $\tau z_{t} h_{t}$ is paid as income tax. In addition, an amount $s \mu_{t}\left(1-z_{t}\right)^{2} h_{t}$ is paid as a transaction cost, to conceal tax evasion. Hence, each citizen's disposable income is

$$
(1-\tau) z_{t} h_{t}+\left(1-z_{t}\right) h_{t}-s \mu_{t}\left(1-z_{t}\right)^{2} h_{t}=\left[\left(1-z_{t} \tau\right)-s \mu_{t}\left(1-z_{t}\right)^{2}\right] h_{t}
$$

The individual optimization problem solved by a citizen born in period $t-1$ is given by

$$
\max _{c_{c t}, z_{t}} c_{c t} h_{t+1}^{\beta}
$$

\footnotetext{
${ }^{14}$ Since most politicians are males, as a mnemonic rule, we use the masculine gender when we refer to the politician and the feminine when we refer to citizens.
} 
subject to

$$
\begin{aligned}
& c_{c t}=\left[\left(1-z_{t} \tau\right)-s \mu_{t}\left(1-z_{t}\right)^{2}\right] h_{t}, \\
& c_{c t} \geq 0, \quad 1 \geq z_{t} \geq 0,
\end{aligned}
$$

taking $H_{t}, E_{t}$, and $\mu_{t}$ as given.

Maximization yields the citizens' best response function:

$$
z_{t}=f\left(\mu_{t}\right)=\left\{\begin{array}{cc}
0 & \text { if } \quad \tau \geq 2 s \mu \\
1-\frac{\tau}{2 s \mu_{t}} & \text { if } \tau<2 s \mu .
\end{array}\right.
$$

Inspection of equation (6) reveals that a corner solution $z_{t}=0$ will emerge if the tax rate $\tau$ is higher than the marginal transaction cost $2 s \mu_{t}$ or, equivalently, if the politician's level of honesty $\mu_{t}$ is below $\tau / 2 s$. Note that the corner $z_{t}=1$ is never feasible for $\tau>0$ and finite $s$. Therefore the citizen always finds it optimal to evade a part of her revenue. Moreover, whenever an interior solution, i.e., $0<z_{t}<1$, emerges, the tax evasion rate $\left(1-z_{t}\right)$ is positively affected by the size of the tax rate $\tau$ and negatively by the cost parameter $(s)$ and, more importantly, the politician's level of honesty $\left(\mu_{t}\right)$. Hence, an increase in the politician's tendency to peculate public funds makes citizens more prone to tax evasion. In other words, the politician's embezzlement rate is a strategic complement for citizens' tax evasion rate, meaning that $z_{t}$ is an increasing function of $\mu_{t}$. The result that the corruption level of one agent may be a strategic complement for another is reminiscent of the argument that corruption is contagious or, as Andvig and Moene (1990) put it, "corruption may corrupt."

The Politician

The politician's optimization problem is

$$
\max _{c_{p t}, \mu_{t}} c_{p t} h_{t+1}^{\beta}
$$

subject to

$$
\begin{aligned}
& c_{p t}=\left(1-\mu_{t} \phi\right) N \overline{z_{t}} \tau H_{t}, \\
& c_{p t} \geq 0, \quad 1 \geq \mu_{t} \geq 0,
\end{aligned}
$$


and equations (1) and (3), taking $\overline{z_{t}}$ and $H_{t}$ as given.

Straightforward maximization yields the politician's best response function

$$
\mu_{t}=g\left(\overline{z_{t}}\right)=\left\{\begin{array}{clcc}
0 & \text { if } & \beta N A \overline{z_{t}} \tau \leq v \\
\frac{\beta N A \overline{z_{t}} \tau-v}{N A \overline{z_{t}} \phi \tau(1+\beta)} & \text { if } & N A \overline{z_{t}} \tau[\beta-\phi(1+\beta)] \leq v<\beta N A \overline{z_{t}} \tau \\
1 & \text { if } & v<N A \overline{z_{t}} \tau[\beta-\phi(1+\beta)] .
\end{array}\right.
$$

Inspection of equation (9) reveals that a corner solution $\mu_{t}=0\left(\mu_{t}=1\right)$ will emerge, if the rate of human capital transferred freely to the next generation, $v$, is sufficiently high (low). Capturing a large (small) percentage of the existing human capital freely implies that the politician, as a parent, has a weak (strong) incentive to invest in education and thus peculates all (none of) the public education funds. Whenever an interior solution emerges, the embezzlement rate $\left(1-\mu_{t}\right)$ is negatively affected by the efficiency of the education system $(A)$, the tax rate $(\tau)$ and the degree of altruism $(\beta)$. On the other hand, the embezzlement rate is negatively affected by the percentage of the tax revenue that is earmarked for politicians' wages $(1-\phi)$. In fact, if $\phi>\beta /(1+\beta)$, then the embezzlement rate is never zero. This accords well with empirical evidence on the negative relationship between corruption and wages (Haque and Sahay 1996).

Finally, an increase in the citizens' average tax evasion rate, $\left(1-\overline{z_{t}}\right)$, increases the politician's embezzlement rate. Put differently, the private citizens' action is a strategic complement for the politician, meaning that $\mu_{t}$ is an increasing function of $\overline{z_{t}}$.

\subsection{Equilibrium}

The situation at hand is a coordination game in which there are strategic complementarities. Games of strategic complementarity (see, for example, Cooper and John, 1988 and Vives, 2005) are those in which the best response of any player, is increasing in the actions of the rival; this is the case here for $\overline{z_{t}}$ and $\mu_{t}$. Strategic complementarity is a necessary condition for the existence of multiple equilibria in symmetric coordination games. The occurring equilibria are not driven by fundamentals. Instead, they are self-fulfilling and critically depend on the expectations of one group concerning the behavior of the other. Nevertheless, the game that we analyze here is not a symmetric game. Moreover the choice space is bounded and this necessitates the consideration of corner solutions. In fact, as 
we show below, this game does not share certain properties of symmetric games with strategic complementarities. Consider first the following definition of the equilibrium:

Definition 1. A Nash equilibrium in this economy consists of sequences $\left\{c_{i t}\right\}_{t=0}^{\infty},\left\{z_{t}\right\}_{t=0}^{\infty}$, $\left\{\mu_{t}\right\}_{t=0}^{\infty},\left\{h_{t}\right\}_{t=0}^{\infty},\left\{H_{t}\right\}_{t=0}^{\infty},\left\{E_{t}\right\}_{t=0}^{\infty}, i=c, p$, such that, given an initial average stock of human capital $H_{0}>0$, in every period $t=0,1,2, \ldots, 1$. Private citizens choose $z_{t}$ to maximize their utility, taking $\mu_{t}, H_{t}$ and $E_{t}$ as given 2. The politician chooses $\mu_{t}$ to maximize his utility, taking $\overline{z_{t}}$ and $H_{t}$ as given 3 . $H_{t}=h_{t}$ and $\overline{z_{t}}=z_{t} \forall t$. The sequences $\left\{h_{t}\right\}_{t=0}^{\infty},\left\{E_{t}\right\}_{t=0}^{\infty}$, and $\left\{c_{i t}\right\}_{t=0}^{\infty}$, are determined according to (1), (3), (5), and (8).

The optimization problem of each agent is well defined since the utility function is strictly concave and the budget constraint is either convex or linear with respect to the relevant decision variable, $z_{t}$ or $\mu_{t}$. In Proposition 1 below, we prove the existence of a pair $\left(z_{t}, \mu_{t}\right)$ that satisfies Definition 1 in every period. Given the existence of the equilibrium pair $\left(z_{t}, \mu_{t}\right)$, we can easily establish the equilibrium values of the remaining variables, following Definition 1.

Proposition 1. An equilibrium pair $\left(z_{t}, \mu_{t}\right)$ exists.

Proof: All proofs are presented in the Appendix.

We call an equilibrium interior (corner) if it lies in the interior (on the boundary) of the unit square. Propositions 2 and 3 establish sufficient conditions for the existence of a unique and multiple equilibria, respectively.

Proposition 2. Uniqueness of the equilibrium

a) If $v=0$ then $\left(z_{t}, \mu_{t}\right)=\left(1-\frac{\tau \phi(1+\beta)}{2 s \beta}, \frac{\beta}{\phi(1+\beta)}\right)$ is the only equilibrium. b) If $s=0$, then $\left(z_{t}, \mu_{t}\right)=(0,0)$ is the only equilibrium. c) If $v \geq \beta A \tau$ or $\tau \geq 2 s$, then $\left(z_{t}, \mu_{t}\right)=(0,0)$ is the only equilibrium.

If $v=0$ then each new generation born in period $t$ will not acquire any human capital unless both $z_{t}>0$ and $\mu_{t}>0$ hold. Thus, the politician commits to a certain strategy regardless of what the citizens do. ${ }^{15}$ Since this is the case, citizens find it optimal not to evade all of their income and therefore an interior solution emerges. On the contrary if there is no transaction cost $(s=0)$, then citizens tax evade their entire income, i.e., $z_{t}=0$, regardless of the politician's action. In this case the corner $(0,0)$ emerges.

\footnotetext{
${ }^{15}$ In Appendix A.2, we analyze a more general version of the model, where both the politician and the citizens pay fines if caught having broken the law. Moreover, the revenue from these fines is spent on public education. We show that, in such a case, strategic complementarity and multiple equilibria can arise even if $v=0$.
} 


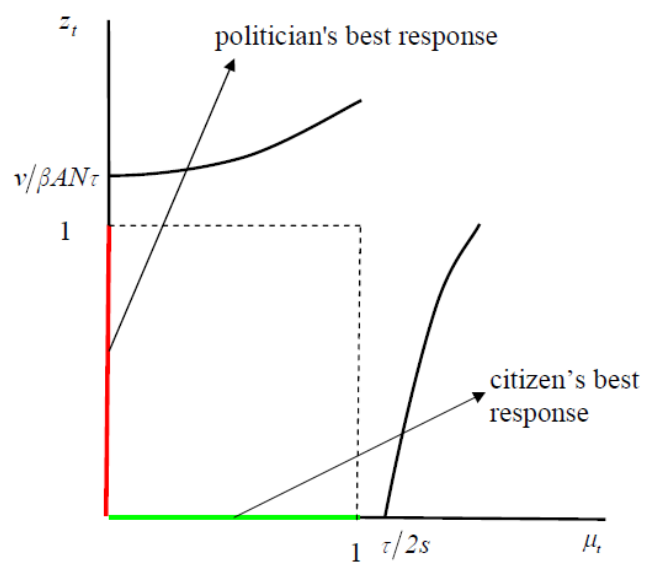

Figure 1. $(0,0)$ is the only equilibrium

If $v$ is high enough and hence each new generation acquires a substantial level of human capital freely, then the politician peculates the entire amount $(\mu=0)$. Anticipating that, the citizens set $z=0$. This case is illustrated in Figure 1, where the relevant segments of the best response functions coincide with the axes. Note that, for a given value of $v$, the condition specified in part (c) of Proposition 2 can also be expressed in terms of the tax rate $(\tau)$. For example, if $\tau$ is too low, then spending on education will be low no matter how honest the politician is. In this case the politician does not have any incentive to behave honestly and hence the only equilibrium is $(0,0)$. This finding is consistent with the positive correlation between corruption, tax evasion and spending on education across countries (Mauro 1995; Tanzi and Davoodi 1997). Nevertheless, it offers a different direction of causality, since spending on education is not low because of high levels of corruption and tax evasion; instead, corruption and tax evasion are at high levels because the commitment for education spending is low.

Similarly, if the tax rate is high enough then the citizens tax evade all their income. This leads again to $(0,0)$ as the only equilibrium. Finally, note that, by analyzing the quadratic equation that results from the combination of (6) and (9), it is straightforward, but tedious, to find additional conditions, which ensure that that the two best response functions intersect only at $(0,0)$, or that they intersect again outside the unit square.

Proposition 3. Multiplicity of equilibria

a) If $v>0$ and $s>0$ then multiple equilibria may always arise. The occurring equilibria can be either one corner and two interior or one interior and two corner, depending on 


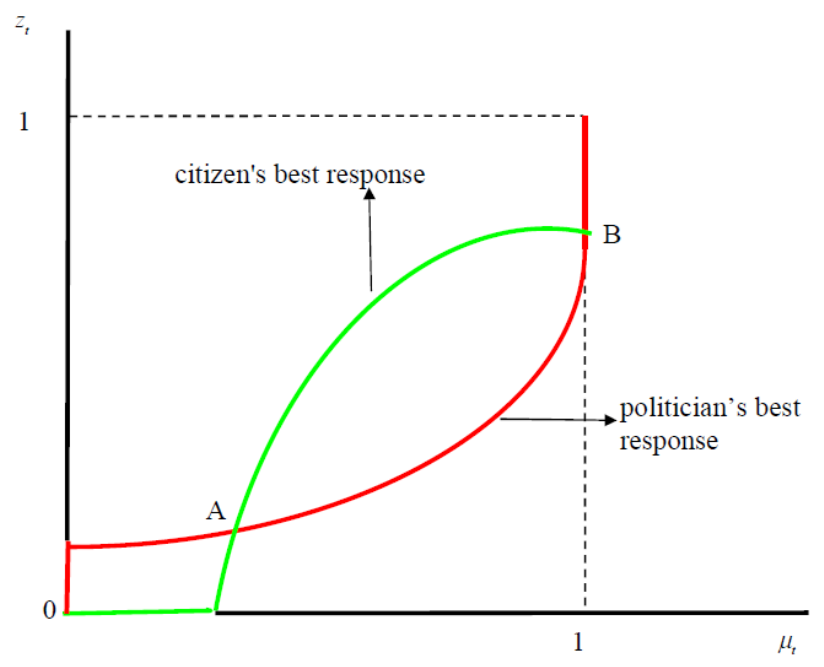

Figure 2. Two corner equilibria

the parameter values. b) If $v>0$, then $\left(z_{t}, \mu_{t}\right)=(0,0)$ is always an equilibrium. c) If $(2 s-\tau) / 2 s>v /[A \tau(\beta-\phi(1+\beta)]>0$, then there exist one interior and two corner equilibria

Figures 2 and 3 show two possible configurations where multiple equilibria arise. Besides the origin, there are two equilibria, which are indicated by the letters $\mathrm{A}$ and $\mathrm{B}$. In Figure 2 there are two corner equilibria and one interior, whereas in Figure 3 there are two interior and one corner equilibrium.

Again, by analyzing the quadratic equation that results from the combination of (6) and (9), it is straightforward but cumbersome to find sufficient conditions for the existence of two interior equilibria or one interior and two corner.

The stability of the equilibria can be characterized using best-reply dynamics; namely, a Nash equilibrium is said to be stable if, starting from any point in its neighborhood, the adjustment process in which players take turns myopically playing a best response to each other's current strategies converges to the equilibrium. Using this approach, we can infer that stability requires that the best response function of the citizen is flatter than that of the politician. Hence, whenever there exist three equilibria, $(0,0)$ and either one interior and one more corner or two interior, the equilibrium that lies in the middle is unstable, while the other two are stable. In sum, there are at most two stable equilibria: $(0,0)$ and the high action equilibrium, where there exists low corruption and low tax evasion. 


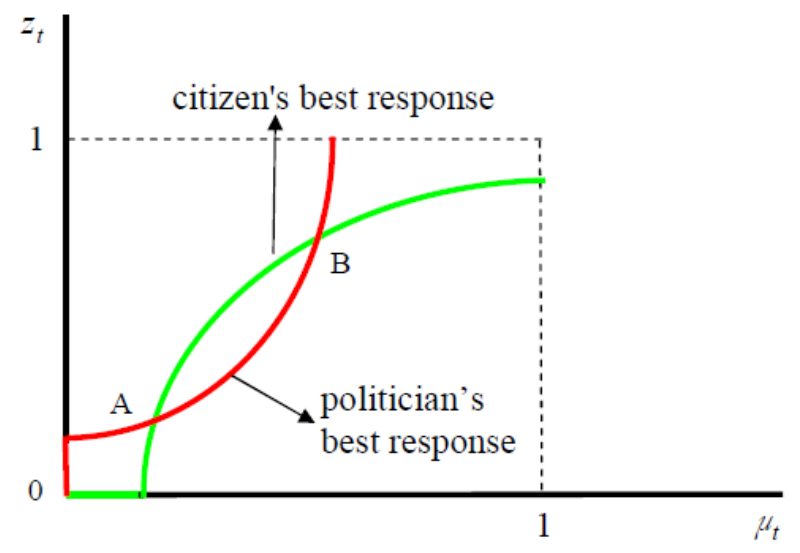

Figure 3. Two interior equilibria

Consider next the following numerical example.

Example 1. Let $A \times N=25, \phi=\tau=0.3, v=0.03, \beta=0.1, s=0.8$. Then there will be one corner equilibrium $\left(\mu_{1}, z_{1}\right)=(0,0)$ and two interior $\left(\mu_{2}, z_{2}\right)=(0.219,0.145)$, and $\left(\mu_{3}, z_{3}\right)=(0.259,0.277)$. The middle equilibrium is unstable while the other two are stable. The utility level of each citizen and the politician in the corner equilibrium and the high action equilibrium, respectively, will be $\left(u_{1 c}, u_{1 p}\right)=(0.704,0)$ and $\left(u_{3 c}, u_{3 p}\right)=$ $(0.685,0.065)$.

Example 1 serves to show, among others, that in contrast, for example, to Cooper and John (1988), if there are two stable equilibria, then, in general, they cannot be ranked in terms of the welfare that they yield. This is attributed to the fact that the game is non-symmetric. The politician is better off at the low corruption and low tax evasion equilibrium $\left(\mu_{3}, z_{3}\right)$ than under the full corruption and complete tax evasion $(0,0)$; the reason is of course that his salary and the amount that he peculates are both a fraction of the tax revenue. Nevertheless, in this particular example, the citizens prefer the first equilibrium, where there is full corruption and complete tax evasion. In general, which equilibrium they prefer depends on the relative strength of two conflicting effects: on the one hand, high tax evasion increases citizen's consumption level, but on the other, it (and the accompanying high corruption) decreases spending on education and hence future levels of human capital. 
Next, we examine some comparative statics related to parameter values.

Proposition 4. If the highest equilibrium $\left(\mu^{*}, z^{*}\right)$ is an interior point, then

$$
\begin{aligned}
& \frac{d \mu^{*}}{d i}>0 \quad \text { and } \quad \frac{d \mu^{*}}{d j}<0 \\
& \frac{d z^{*}}{d i}>0 \quad \text { and } \quad \frac{d z^{*}}{d j}<0
\end{aligned} \quad \text { where } i=s, A, \beta \text { and } j=\phi, v .
$$

The effects of a change in the tax rate $\tau$ are ambiguous.

The intuition behind these results is straightforward. For example, an increase in $s$ raises the cost of tax evasion and hence $z^{*}$. Given the strategic complementarity, $\mu^{*}$ increases as well. An increase in $A$, on the other hand, raises the efficiency of public education and hence $\mu^{*}$. The effect on $z^{*}$ follows again from the strategic complementarity of the two actions. Finally, an increase in the tax rate has ambiguous effects, because, on the one hand, it raises the incentives for tax evasion but, on the other, it increases spending on education and thus the human capital of the next generation.

Corollary 1. If $v>0$ then changes in the policy instruments, i.e., changes in $\tau, s$ or $\phi$, cannot eliminate the high corruption equilibrium $(0,0)$.

As long as some of the knowledge is transferred freely to the new generations, then the politician may peculate all the public funds. Anticipating that, citizens may declare zero income.

Overall, it is interesting to note that in a context where corruption may corrupt, multiple self-fulfilling equilibria may arise that cannot be eliminated via the use of policy. This can explain why corruption may persist. In the following section, we enrich the benchmark model to examine whether standard policies are effective in eliminating endemic corruption.

\section{Enforcement Policy}

In this section we analyze standard deterrence policies. Accordingly, suppose that both citizens and the politician are faced with a certain probability of being audited. To keep the analysis simple, in the main text, we assume exogenous auditing probabilities and fines. ${ }^{16}$ If they are audited, then their illegal action is revealed and they are punished with a fine.

\footnotetext{
${ }^{16}$ In Appendix A.2 we attempt to endogenize the auditing probabilities.
} 
More specifically, let $p$ denote the expected penalty rate, i.e., $p$ equals the probability of being audited times the penalty rate. Then, the budget constraint of each citizen is

$$
c_{c t}=\left[\left(1-\tau z_{t}\right)-s \mu_{t}\left(1-z_{t}\right)^{2}-p \tau\left(1-z_{t}\right)\right] h_{t} .
$$

The first term inside the brackets on the right-hand side of $(10),\left(1-\tau z_{t}\right) h_{t}$, is the citizen's disposable income; she has income $h_{t}$ and pays taxes equal to $\tau z h_{t}$. The second term, $s \mu_{t}\left(1-z_{t}\right)^{2} h_{t}$, is the transaction cost of tax evasion. Finally, the last term, $p \tau\left(1-z_{t}\right) h_{t}$, is the expected penalty, which is proportional to the evaded tax as in Yitzhaki (1974). ${ }^{17}$ Moreover, as it is common in this literature, e.g., Chen (2003), we assume that the tax evasion gamble is better than fair, i.e., $p \leq 1 .^{18}$

Similarly, the politician, if found to have embezzled pubic funds, pays a fine that is proportional to the embezzled amount. ${ }^{19}$ We let $q$ denote the expected punishment rate. Hence, the politician's budget constraint is

$$
c_{p t}=\left(1-\mu_{t} \phi\right) N \overline{z_{t}} \tau H_{t}-q\left(1-\mu_{t}\right) \phi N \overline{z_{t}} \tau H_{t} .
$$

It may be recalled that the total tax revenue collected within a period $t$ is $R_{t}=N \overline{z_{t}} \tau H_{t}$. Equation (11) sets the consumption of a politician, $c_{p t}$, equal to his salary, $(1-\phi) R_{t}$, plus the embezzled amount of public funds, $\left(1-\mu_{t}\right) \phi R_{t}$, minus the expected fine, $q\left(1-\mu_{t}\right) \phi R_{t}$. As is the case with citizens, the embezzlement gamble is assumed to be better than fair, i.e., $q \leq 1$.

The law of motion of human capital is still given by (1) and $E_{t}$ is again given by (3). ${ }^{20}$

\subsection{Individual optimization}

\section{Citizens}

\footnotetext{
${ }^{17}$ Imposing fines on evaded income, following Allingham and Sandmo (1972), leads to qualitatively similar results.

${ }^{18}$ The case where the opposite holds is of little interest, since tax evasion would never take place. The assumption that the evasion gamble is better than fair, is empirically supported; see, for example, Skinner and Slemrod (1985). The most plausible interpretation of this is that the penalty rate is greater than one, the probability of inspection is less than one, and the product of the two also less than.

${ }^{19}$ In Appendix A.2 we analyze an extreme case of penalty, where a corrupt politician has zero consumption (he is thrown out of office). As we show, our results remain qualitatively the same.

${ }^{20}$ In Appendix A.2, we analyze also the case where the revenue from the fines imposed on tax dodgers and corrupt politicians is spent on public education. Once again, our results remain essentially unaltered. In fact, as mentioned above in footnote 15, multiple equilibria arise even if $v=0$.
} 
The individual optimization problem solved by each citizen at time $t$ is that of maximizing (4) subject to (10) and the non-negativity constraints, taking $H_{t}, E_{t}$, and hence $h_{t+1}$, and $\mu_{t}$ as given. To simplify the algebra, in the remainder of the paper we assume that $\beta=1$. Maximization yields

$$
z_{t}=f\left(\mu_{t}\right)=\left\{\begin{array}{ccc}
0 & \text { if } \quad \tau \geq \frac{2 s \mu_{t}}{1-p} \\
1-\frac{(1-p) \tau}{2 s \mu_{t}} & \text { if } \quad \tau<\frac{2 s \mu_{t}}{1-p} .
\end{array}\right.
$$

As in the benchmark model, the politicians' embezzlement rate is a strategic complement for citizens' tax evasion rate, meaning that $z_{t}$ is an increasing function of $\mu_{t}$. The general properties of the reaction function are similar to the those of the benchmark model. Moreover, when we compare the interior solution with the one in the benchmark model, we observe that for the same value of $\mu_{t}$, the evasion rate $z_{t}$ is lower.

\section{The Politician}

The politician maximizes (7) subject to (11), the non-negativity constraints and equations (1) and (3), taking $\overline{z_{t}}$ and $H_{t}$ as given. Maximization yields

$$
\mu_{t}=g\left(\overline{z_{t}}\right)=\left\{\begin{array}{clc}
0 & \text { if } & N A \tau \overline{z_{t}}(1-\phi q) \leq(1-q) v \\
\frac{N A \tau \overline{z_{t}}(1-\phi q)-v(1-q)}{2 N A \phi \tau \overline{z_{t}}(1-q)} & \text { if } & N A \tau \overline{z_{t}}(1-2 \phi+\phi q)<(1-q) v<N A \tau \overline{z_{t}}(1-\phi q) \\
1 & \text { if } & (1-q) v \leq N A \tau \overline{z_{t}}(1-2 \phi+\phi q) .
\end{array}\right.
$$

Simple differentiation shows that $d \mu_{t} / d \overline{z_{t}}>0$ and hence private citizens' action is a strategic complement for the politician. The general properties of the reaction function are similar to the those of the benchmark model. Moreover, when we compare the interior solution with the one in the benchmark model, we observe that for the same value of $z_{t}$, the embezzlement rate $\mu_{t}$ is lower.

\subsection{Equilibrium}

The definition of equilibrium remains basically the same as that in Definition 1. Also, following exactly the same steps as in Proposition 1 we can show the existence of an 
equilibrium in this version of the model as well. For a wide range of parameter values there exist three equilibria, one corner and two interior or one interior and two corner. The stability of the equilibria is the same as in the benchmark model, namely the lowest (full tax evasion and full corruption) and the highest (low tax evasion and low corruption) equilibria are stable, whereas the intermediate equilibrium is unstable. Crucially while deterrence policies are successful in reducing corruption and tax evasion in the low corruption equilibrium still though the multiplicity persists.

The intuition behind this result lies in that deterrence policies can affect agents' decision with respect to their own budget constraint since they simply render evasion or embezzlement more costly. Still though they fail to treat the problem arising due to presence of strategic interactions. No matter how high a fine or an auditing probability is, whenever agents expect other agents to be corrupt, they always find it optimal to be corrupt as well. ${ }^{21}$

The argument advanced by this section is that deterrence policies are limited in scope if they are the only means employed in the fight against corruption. If the economy coordinates to the low corruption equilibrium, then this will be a better equilibrium than the one without deterrence. However, so long as the policy does not break the strategic compementarity in corrupt actions, there is no guarantee that the economy will coordinate to the good equilibrium. No matter how high the expected fines will be, it might always be beneficial for one group to remain corrupt if the other group remains corrupt too. Despite the inherent difficulties in quantifying these policies, the fact that a number of developed countries such as EU members, which not only have advanced deterrence systems but are also part of a union that provides general guidelines for the fight against corruption, ${ }^{22}$ exhibit very different outcomes, is suggestive of the fact that different countries may coordinate to different equilibria.

\footnotetext{
${ }^{21}$ One can argue that since the government knows the amount of tax revenue and since all taxpayers are identical, it could easily observe that all taxpayers evade and thus set $p=1$. To justify a probability of detection lower than unity we could either introduce a fraction of honest taxpayers (which would unnecessarily complicate our results) or assume that $p$ denotes the probability that the true evasion rate is revealed (Andreoni et al, 1998).

${ }^{22}$ http://www.socialistsanddemocrats.eu/gpes/media3/documents/3842_EN_richard_murphy_eu_tax _gap_en_120229.pdf
} 


\section{Norms, Morals and Values}

One of the main reasons that may prevent a society from coordinating around the low corruption and low tax evasion equilibrium is the luck of trust, which seems to be present in many societies. In a context where some form of "legitimization" of corrupt norms prevails, it seems natural to resort to a strengthening of the morals of the society in an effort to mitigate the strategic complementarity effects. This strengthening of the morals of the society can actually lead to better enforcement of standard deterrence policies. ${ }^{23}$

\subsection{Social Stigma Cost}

Following, Kim (2003) among others, we postulate that when law-breaking agents are traced, they suffer a disutility from being revealed as cheaters. To keep the analysis simple we assume that there are no fines for tax dodgers and corrupt politicians. We seek to examine whether coordination can be achieved if suitable values are inculcated upon agents.

\section{Citizens}

Each citizen's utility function is now modified as follows:

$$
\max _{c_{t}^{c}, z_{t}} c_{t}^{c} h_{t+1}-\gamma H_{t}\left(1-z_{t}\right) \tau h_{t}
$$

The last term in (14) captures the expected size of the moral cost if the citizens gets caught. This term depends positively on the total tax that the delinquent evaded, $(1-z) \tau h_{t}$. Analytically, the expected marginal cost of breaking the law is $\gamma H_{t}$. The parameter $\gamma>0$ is of special interest because it measures the expected punishment that the society inflicts upon law-breaking activities. It is influenced by the level of moral values in the society, i.e., the society's sensitivity to tax evasion, as well as the probability of being caught. ${ }^{24}$

\footnotetext{
${ }^{23}$ The notion of morals is not new in the economics literature and has been widely used in various contexts. For example, Moffit (1983) and Besley and Coate (1992) analyze the case where there is a moral stigma for people who participate in welfare programs. In the tax evasion literature the notion was first introduced by Allingham and Sandmo (1972). Recently, Kim (2003) has analyzed the case where society views tax evasion as an ignominious behavior and places a social stigma upon agents that are disclosed as tax evaders. Alm and Torgler (2011) suggest several alternative ways by which the theory of tax compliance can be extended to incorporate ethics.

${ }^{24}$ We implicitly assume that the moral cost is an intrinsic cost (see, among others, Gordon 1989 and Benabou and Tirole 2003) not associated with other groups' behavior. In an extension of the model we have associated individual cost with other groups' behavior (following the rationale we adopted for the transaction cost) and found qualitatively similar results.
} 
Furthermore, we assume that the expected marginal moral cost depends on the average level of human capital, $H_{t}$. There is a technical reason behind this assumption. Without this, as the levels of human capital and income grow over time, the expected marginal benefit from breaking the law increases, whereas the expected marginal cost remains constant. As a result, after a certain level of human capital, the expected marginal benefit outweighs the marginal cost and the moral cost becomes irrelevant. Nevertheless, we think that this may not be an inappropriate assumption, since different societies may judge the same unlawful act in a different manner. For example, poor societies may be more tolerant towards tax evasion and not view it as unethical. In any case, even if we drop this assumption, our results below still hold for low levels of human capital, or if the level of human capital remains constant over time (i.e., a steady-state equilibrium in levels instead of the growth rates).

A citizen maximizes (14) subject to (5) and the non-negativity constraints, taking $\mu_{t}$, $E_{t}$ and $H_{t}$ as given. The citizens' best response function is now far more complicated. It is given in an implicit form in Appendix A.2. Moreover, the nature of the interaction between citizens and the politician is not clear any more. Specifically, for low values of $\gamma$, we have that $d z_{t} / d \mu_{t}$ is unambiguously positive as before, i.e., the politician's action is definitely a strategic complement for the citizens (the threshold value of $\gamma$ is given in Appendix A.2). Nevertheless, for high value of $\gamma$, when the effect of moral cost is strong, the politician's action may become a strategic complement for citizens.

\section{The Politician}

The politician's optimization problem at time $t$ is now given by

$$
\max _{c_{t}^{p}, \mu_{t}} c_{t}^{p} h_{t+1}-\gamma H_{t}\left(1-\mu_{t}\right) N \phi \tau \overline{z_{t}} H_{t}
$$

subject to the budget constraint (8), the standard non-negativity constraints and equations (1) and (3), taking $\overline{z_{t}}$ and $H_{t}$ as given. The moral cost term in (15) is completely analogous to the one introduced above in citizens' utility (equation 14). First, it depends positively on the size of the fraud $\left(1-\mu_{t}\right) N \tau \phi \overline{z_{t}} H_{t}$. Second, the expected marginal cost $\gamma H_{t}$ depends positively on the average human capital. Finally, for simplicity, we assume that the value of $\gamma$ is the same with that in the citizens' problem.

Maximization yields the solution 


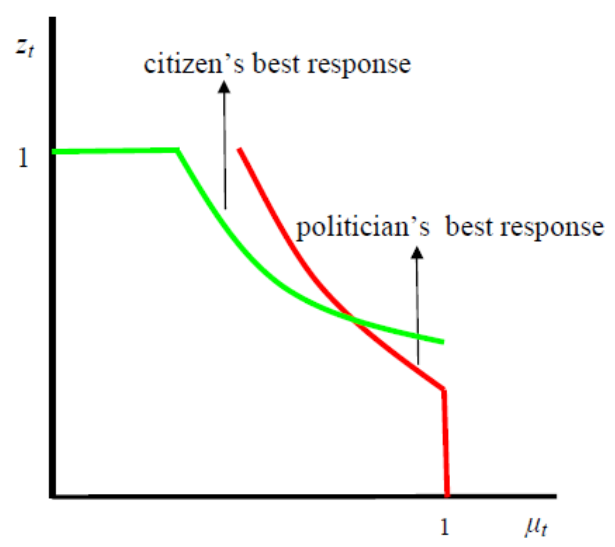

Figure 4. Equilibrium in a stigma-based society

$$
\mu_{t}=g\left(\overline{z_{t}}\right)=\left\{\begin{array}{cccc}
0 & \text { if } & N A \tau \overline{z_{t}} \leq v-\gamma \\
\frac{N A \tau \overline{t_{t}}+\gamma-v}{2 N A \phi \tau \overline{z_{t}}} & \text { if } & N A \tau \overline{z_{t}}(1-2 \phi)<v-\gamma<N A \tau \overline{z_{t}} \\
1 & \text { if } & v-\gamma<N A \tau \overline{z_{t}}(1-2 \phi) .
\end{array}\right.
$$

Notice that for values of $\gamma$ below $v, d \mu_{t} / d \overline{z_{t}}>0$ as before. Nevertheless, for values of $\gamma$ above $v, d \mu_{t} / d \overline{z_{t}}<0$, namely, the citizens' action is a strategic substitute for the politician. This means that if the stigma cost for following an unlawful action is high enough, then the politician does not wish any more to respond positively to the action of the citizens; instead he attempts to improve the situation by choosing to be more honest.

The definition of equilibrium is similar to that in the previous versions. Notice that if we set $\gamma=0$, then this version collapses to the benchmark model. More generally, for sufficiently small values of $\gamma$ we get the same results as in the benchmark model. For sufficiently high values of $\gamma$, however, the action of the politician may be a strategic substitute for the citizens and vice versa. We illustrate this case in the following example. Example 2. Let $A N=2, \phi=0.7, \tau=0.4, v=0.04, s=0.8$, and $\gamma=0.1$. Then the best response functions have the properties shown in Figure 4. Moreover, there exists a unique interior equilibrium: $\left(\mu^{*}, z^{*}\right)=(0.782,0.790)$.

We can conclude that a stigma cost is possible to eliminate the multiplicity of equilibria. Contrary to simple deterrence policies, a stigma cost that is high enough alters 
agents' behavior, since each agent's action may now be a strategic substitute, instead of a strategic complement, to other agents. ${ }^{25}$

As mentioned above, the parameter $\gamma$, which enters in the expected marginal moral cost, depends on two terms: the level of moral values in the society and the probability of being caught. The first is the result of education, anti-corruption campaigns and public exhortation, while the second is a policy instrument. Nevertheless, both of these factors are crucial for the effectiveness of social stigma and one cannot work without the other.

\subsection{Discussion}

A critique of our results could be that we exogenously assume that agents suffer from moral costs if they get caught cheating. This would be true taking into account that the establishment of internal moral costs, if feasible, is a long-term solution, since it requires a change in agents' attitudes and tastes. However, our purpose is to examine the effectiveness of various policies on the deterrence of corruption assuming they are successfully implemented. Whether a policy will be successfully implemented or not depends on many factors that cannot be easily accounted for in a model, not even for standard policies such as fines and auditing probabilities. We have therefore followed the standard morals literature (see, Moffit 1983; Gordon 1989; Besley and Coate 1992; Kim 2003) and assumed that if an agent is audited and exposed as an evader (embezzler) she suffers from an internal moral cost. Interestingly we found that in the presence of a sufficiently high cost we can eliminate the multiplicity of equilibria. The mechanism behind our results is breaking the "social legitimization" effect and rendering the strategies of the players strategic substitutes. Strategic substitutability implies that it is too costly for agents to follow the other agents' actions.

Anti-corruption campaigns are often employed by countries in the fight against corruption and aim at increasing awareness and sensitiveness of the public. One of the first nation-wide anti-corruption campaign was the so-called San Fan (the Three Anti) that was initiated in China in 1951. The three "antis" promoted were anti-corruption, anti-waste and anti-bureaucracy. The "Three Anti" Campaign was followed by the "Five Anti" Campaign that was launched in 1952 and promoted anti-bribery, anti-theft of state

\footnotetext{
${ }^{25}$ Note that this simplifying formulation aims at highlighting the role of stigmatizing offenders when implementing anti-corruption policies. Evidently if a deterrence policy involves both a pecuniary and a non-pecuniary (stigma) cost, then we would obtain qualitatively similar results. Specifically, we could still eliminate multiplicity, but this would be the outcome of the stigmatizing effect of the policy.
} 
property, anti-tax evasion, anti-cheating on government contracts and anti-stealing state economic information (Spence, 1991). All citizens and particularly members of the Chinese Communist Party were mobilized to inspect and report corrupt activities. Offenders were widely exposed and in some instances severely punished. The outcome of the first campaign was a significant decrease in corruption; thus, it can be inferred that the policy was initially successful. Nevertheless, the second campaign was eventually misused as an action against political opponents and was eventually abandoned without significant achievements (see, Spence, 1991).

In India a tax amnesty took place in 1997, which was highly successful and brought a substantial increase in revenue, mostly because the state had hired two marketing companies that used moral suasion to increase tax compliance (Torgler, 2004). To increase peer pressure on tax evaders, governments often make publicly available the tax filling reports or publicize cases of tax evasion. For example, in Sweden, Norway and Finland personal income tax fillings are publicly available (see Lenter et al., 2003) ${ }^{26}$ In California, on the other hand, the names of the top 500 delinquent taxpayers are published on the internet annually. ${ }^{27}$ Also, the U.S. Attorney's office in the district where a case is prosecuted "normally issues a press release when a tax evader is indicted, once he or she is convicted, and again when the evader is sentenced" (Gray, 1999). In New Zealand the Commissioner of Inland Revenue regularly releases the "Tax Evaders Gazette," which lists those taxpayers, individuals and companies, who have been prosecuted, had penal tax or shortfall penalties imposed for evading their tax obligations (see Lenter et al., 2003). Several other countries follow similar practices. ${ }^{28}$ The purpose of all these actions is to increase the moral cost, via the use of peer-pressure, and eventually to inculcate a culture of tax compliance.

\footnotetext{
${ }^{26}$ In fact, in Norway tax fillings are available on the Internet for both individuals and corporations.

${ }^{27}$ See https://www.ftb.ca.gov/aboutFTB/Delinquent_Taxpayers.shtml. In fact, since the inception of this program in 2007 and as of March 25, 2013, the State of California Franchise Tax Board has recovered more than $\$ 216$ million in revenue from taxpayers that came forward to take care of their debts.

${ }^{28}$ Interestingly, the Hellenic Data Protection Authority, an independent authority in charge of the protection of data privacy in Greece, has recently ruled against the publication of the names of individual delinquent taxpayers.
} 


\section{Empirical Analysis}

\section{$5.1 \quad$ Strategy}

The empirical section of the paper is developed in two parts. In the first part, the analysis establishes a correlation between attitudes towards tax evasion and perceived political corruption, highlighting the interaction derived from our theoretical analysis. Next, we would like to ascertain that this correlation is not driven by unobservables. For this purpose, in the second part, we use a sample of second and third generation migrants and estimate a causal effect of the mean perception of political corruption in the home country on attitudes towards tax evasion, as expressed by migrants currently residing in the US.

\subsubsection{World Values Survey}

This section establishes that, in line with our theoretical findings, attitudes towards tax evasion are positively correlated with the perceived level of political corruption, i.e., the higher the extent of perceived political corruption, the more justifiable citizens find it to cheat on taxes. Causality runs both ways and in this section we do not attempt to address the issue of endogeneity; we just establish a positive correlation between the two, even after controlling for a large number of individual controls as well as country and time fixed effects.

In particular, we estimate the following reduced form equation:

$$
T E_{i j t}=\alpha_{1}+\alpha_{2} \mathbf{P C}_{i}+\alpha_{3} \mathbf{X}_{i}+\mathbf{I}_{j}+\mathbf{Y}_{t}+\varepsilon_{i j t}
$$

where $T E_{i j t}$ is the individual responses to how justifiable it is to cheat on taxes, $i$ corresponds to the individual, $j$ denotes the country and $t$ denotes the World Values Survey (WVS) round during which the individual was interviewed. $X_{i}$ is a vector of individual controls (age, age square, gender, employment status), $I_{j}$ is a vector of country fixed effects capturing any unobservables that remain constant over time at the country level, whereas $Y_{t}$ is a vector of WVS round fixed effects capturing any unobservable time shocks associated with the timing of the interview. $\varepsilon_{i j t}$ is the error term, whereas standard errors are clustered at the country dimension. 


\subsubsection{General Social Survey-Migrants Sample}

This section argues that the interaction between perceived political corruption and individual attitudes towards tax evasion, established in the previous section, is not spurious and not driven by endogeneity. To this end, our identification strategy exploits the natural experiment of migration. In particular, we use a sample of migrants who currently reside in the US and are thus faced with the same sociopolitical environment. In order to mitigate the issue of selective migration and of unobservables in the home country, we use the sample of second and third generation migrants, who were not selected into the host country and have no interaction with their origin country, other than the culture instilled to them by their parents. Thus, any differences that we pick among attitudes of migrants are primarily driven by cultural differences among them (see Fernandez and Fogli 2009; Luttmer and Singhal 2011).

We estimate the following equation:

$$
T E_{i o t}=\alpha_{1}+\alpha_{2} \mathbf{P C}_{o}+\alpha_{3} \mathbf{X}_{i}+\mathbf{Y}_{t}+\varepsilon_{i o t}
$$

where $T E_{\text {iot }}$ is the individual response as to how justifiable it is to cheat on taxes, $i$ corresponds to the individual, $o$ denotes the country of origin and $t$ denotes the General Social Survey (GSS) round during which the individual was interviewed. $X_{i}$ is a vector of individual controls (age, age square, gender, employment status), and $Y_{t}$ is a vector of GSS round fixed effects capturing any unobservable time shocks associated with the timing of the interview. $\varepsilon_{i o t}$ is the error term, whereas standard errors are clustered at the country of origin dimension.

\subsection{The Data}

The empirical section adopts individual data from two survey data sets, the World Values Survey and the General Social Survey.

\subsubsection{World Values Survey}

The first part of the analysis, which establishes a correlation between political corruption and tax evasion, uses two waves from the WVS for which the full set of controls is available, namely, the 1994-1999 round and the 2005-2007 round. The sample includes 
$N=54555$ individuals from 45 countries. The countries employed in the sample are Albania, Azerbaijan, Argentina, Australia, Bangladesh, Armenia, Bosnia and Herzegovina, Brazil, Bulgaria, Belarus, Chile, Colombia, Czech Republic, Dominican Republic, El Salvador, Estonia, Finland, FYROM, Georgia, Germany, India, Latvia, Lithuania, Mexico, Moldova, New Zealand, Nigeria, Norway, Peru, Poland, Puerto Rico, Romania, Russian Federation, Serbia and Montenegro, Slovakia, South Africa, South Korea, Spain, Sweden, Switzerland, Taiwan, Ukraine, the United States, Uruguay, and Venezuela.

We focus on two main questions from the WVS. The first question is "How widespread do you think bribe taking and corruption is in this country?" and is related to the extent of political corruption (as perceived by individuals). The variable is ranked from 1 to 4 with 1 denoting "Almost no officials involved in it" and 4 denoting "Almost all public officials are involved in it".

The second question, which is related to tax evasion, is "Please tell me for each of the following statements whether you think it can always be justified, never be justified, or something in between, using this card: Justifiable to cheat on taxes". The variable is ranked from 1 to 10 with 1 denoting "Never justifiable" and 10 denoting "Always justifiable".

Interestingly, both variables reflect perceptions of corruption as well as the extent of legitimization associated with corruption. The additional controls included are the age of the respondent, the gender, educational level, religious group and other individual variables available from the WVS.

\subsubsection{General Social Survey}

The second part of the empirical analysis, which seeks to address the issue of endogeneity, employs the sample of migrants from the General Social Survey (GSS) data set. The GSS spans over the period 1972-2012 and is conducted annually. The survey, among other things, provides information as to the ethnic origin of the participating individuals. Our analysis exploits only the sample of second and third generation migrants (first generation migrants are excluded to mitigated the concern of omitted variable bias and selection). In particular there are $N=197$ migrants from 16 countries for which the full set of controls is available, namely, Czech Republic, Germany, Hungary, Lithuania, Mexico, Norway, Philippines, Poland, Portugal, Puerto Rico, Romania, Russia, Spain, Sweden, Switzerland and the UK. 
TABle 1: Countries of Origin of the 2nd, 3rd and 4th Generation Migrants

\begin{tabular}{lclc}
\hline \hline & & & \\
\hline Family Origin & Frequency & Family Origin & Frequency \\
\hline Czech Rep. & 10 & Portugal & \\
Germany & 58 & Puerto Rico & 3 \\
Hungary & 7 & Romania & 2 \\
Lithuania & 3 & Russia & 17 \\
Mexico & 15 & Spain & \\
Norway & 12 & Sweden & 5 \\
Philippines & 1 & Switzerland & 1 \\
Poland & 30 & UK & 33 \\
\hline Total & & \multicolumn{2}{c}{197} \\
\hline
\end{tabular}

Summary: The table lists the countries of origin for the sample of second and third generation migrants, as well as the number of migrants coming from each source country.

In order to identify the second and third generation migrants, we use two questions from the GSS on how many parents and grandparents were born in the US. The question on parents' origin is ranked as follows: 0 if both parents of the migrant are born in the US, 1 if only the mother was born in the US and 2 if only the migrant's father was born in the US. This questions allows us to identify the second generation migrants.

The variable on the origin of grandparents takes the value of 0 if all grandparents were born in the US, the value 1 if at least one was born outside the US, 2 if two were born outside the US, 3 if three were born outside the US and 4 if all four grandparents were born outside the US. The combination of these two variables allows us to trace migrants up to four generations. Therefore, second generation migrants are those who were born in the US and at least one parent was born abroad and all grandparents were born abroad. Third generation migrants are those who were born in the US, whose parents were born in the US and at least two grandparents were born abroad.

To trace the ethnic origin of the individuals, we use the question that asks them to rank the three ethnic origins to which they feel closer too. We always use as the ethnic origin of the individual his/her first choice.

The question that is related to the attitudes of migrants towards corruption is phrased as "It is wrong to cheat on taxes". The variable takes values from 1 to 4 with 1 denoting "seriously wrong" and 4 denoting "not wrong". 


\subsection{Findings}

\subsubsection{World Values Survey}

Column (1) of Table 2 regresses individual attitudes of tax evasion on the perceived level of corruption of politicians without using any controls and thus exploiting cross country variation. The coefficient is positive and highly significant, thereby uncovering the interaction between political corruption (as perceived by individuals) and individual attitudes towards tax evasion. Column (2) introduces into the analysis country and WVS round fixed effects to capture any unobservables associated with the country or the year during which the survey has been conducted and thus exploiting within country variation. Although the coefficient decreases somewhat in magnitude, yet it remains highly significant. Column (3) introduces into the analysis exogenous individual controls such as age and a quadratic term on age as well as gender. Finally, Column (4) introduces controls for the income and the educational level of the individual. Reassuringly, the results remain intact and the coefficients remain basically constant.

Overall the findings of Table 2 confirm the theoretical predictions of our analysis, i.e., that political corruption interacts with tax evasion. The table provides mere correlations, which, nevertheless, indicate that the two effects feedback on each other and can drive countries into a vicious circle where different forms of corruption interact with one another.

\subsubsection{General Social Survey}

The theoretical predictions of the model highlight the interaction and thus the correlation between the two forms of corruption. Yet, it is crucial to make sure that the correlation highlighted in the previous section does not pick up the effect of any unobservables. That is why, in this section, we attempt to establish the causal effect of perceived political corruption on individual attitudes towards tax evasion.

Table 3 illustrates the results of regressing individual attitudes with respect to tax evasion on the mean value of the perceived level of corruption of politicians in the origin country. Column (1) does not introduce any controls. The coefficient is positive and highly significant, thereby uncovering the interaction between political corruption (as perceived by individuals) and individual attitudes towards tax evasion. Column (2) introduces into the analysis individual controls, such as gender and age as well as GSS round fixed 
TABle 2: Interpersonal Trust

\begin{tabular}{lcccc}
\hline \hline \multicolumn{1}{c}{$(1)$} & $(2)$ & $(3)$ & $(4)$ \\
\hline & \multicolumn{5}{c}{ Justifiable to Cheat on Taxes } \\
\hline Corruption of Politicians & $0.212^{* * *}$ & $0.122^{* * *}$ & $0.115^{* * *}$ & $0.117^{* * *}$ \\
& $(0.060)$ & $(0.036)$ & $(0.034)$ & $(0.033)$ \\
Age & & & $-0.023^{* * *}$ & $-0.026^{* * *}$ \\
& & & $(0.006)$ & $(0.006)$ \\
Age Square & & & 0.000 & 0.000 \\
& & & $(0.000)$ & $(0.000)$ \\
\hline WVS Round FE & No & Yes & Yes & Yes \\
\hline Country FE & No & Yes & Yes & Yes \\
\hline Gender & No & No & Yes & Yes \\
\hline Income & No & No & No & Yes \\
\hline Education & No & No & No & Yes \\
\hline No. of Countries & 45 & 45 & 45 & 45 \\
\hline Obs. & 54555 & 54555 & 54555 & 54555 \\
\hline R-sq. & 0.006 & 0.081 & 0.098 & 0.108 \\
\hline
\end{tabular}

Summary: This table establishes that the more corrupt politicians are perceived to be, the more individuals justify tax evasion. The analysis controls for individual characteristics such as age, age square, gender, educational level and income as well as for country and WVS round fixed effects. Notes: (i) The question on the extent of political corruption (as perceived by individuals) is captured by the question "How widespread do you think bribe taking and corruption is in this country?". The variable is ranked from 1 to 4 with 1 denoting "Almost no officials involved in it" and 4 denoting "Almost all public officials are involved in it"; (ii) the question related to tax evasion is "Please tell me for each of the following statements whether you think it can always be justified, never be justified, or something in between, using this card: Justifiable to cheat on taxes". The variable is ranked from 1 to 10 with 1 denoting "Never justifiable" and 10 denoting "Always justifiable"; (iii) robust standard error estimates, clustered at the country dimension, are reported in parentheses; (iv) *** denotes statistical significance at the 1 percent level, ${ }^{* *}$ at the 5 percent level, and ${ }^{*}$ at the 10 percent level, all for two-sided hypothesis tests. 
effects. Column (3) introduces into the analysis additional exogenous individual controls, such as income and education. Column (4) controls for maternal and paternal education to capture potential effects associated with the transmission channel, i.e., the transmission of culture from parents to children. Reassuringly, the results remain largely intact both in magnitude and in significance, confirming the causal effect of political corruption on tax evasion.

Finally, Column (5) extends the analysis to the full sample of migrants. Although this comes at the expense of exogeneity, since it incorporates first generation migrants, it has the advantage that it raises the size of the sample. As shown in Table 3, the coefficient remains significant at the $5 \%$ level despite the fact that the sample also allows for the presence of fourth generation migrants where the transmission is weaker.

Overall, the findings of Table 3 confirm the theoretical predictions of our analysis, as well as the findings of the previous section, i.e., that political corruption interacts with tax evasion. By using the sample of second and third generation migrants, the analysis ensures that the result is not driven by unobservables. 
TABLE 3: Interpersonal Trust

\begin{tabular}{lccccc}
\hline \hline & $(1)$ & $(2)$ & $(3)$ & $(4)$ & $(5)$ \\
\hline \multicolumn{7}{c}{ Justifiable to Cheat on Taxes } \\
\hline Mean Political Corruption (Origin Country) & $0.410^{* * *}$ & $0.415^{* *}$ & $0.400^{* *}$ & $0.416^{* * *}$ & $0.211^{* *}$ \\
& $(0.123)$ & $(0.163)$ & $(0.142)$ & $(0.138)$ & $(0.084)$ \\
Age & & -0.017 & -0.017 & -0.018 & -0.004 \\
& & $(0.013)$ & $(0.012)$ & $(0.011)$ & $(0.008)$ \\
Age Square & & 0.000 & 0.000 & $0.000^{*}$ & 0.000 \\
& & $(0.000)$ & $(0.000)$ & $(0.000)$ & $(0.000)$ \\
& & & & & \\
\hline GSS Round FE & No & Yes & Yes & Yes & Yes \\
\hline Gender & No & Yes & Yes & Yes & Yes \\
\hline Income & No & No & Yes & Yes & Yes \\
\hline Education & No & No & No & Yes & Yes \\
\hline Paternal-Maternal Education & No & No & No & Yes & Yes \\
\hline All Migrants & No & No & No & No & Yes \\
\hline No. of Origin Countries & 15 & 15 & 15 & 15 & 17 \\
\hline Obs. & 197 & 197 & 197 & 197 & 750 \\
\hline R-sq. & 0.038 & 0.066 & 0.069 & 0.077 & 0.014 \\
\hline
\end{tabular}

Summary: This table establishes that the more corrupt politicians are perceived to be at the origin country, the more individuals justify tax evasion in the host country. The analysis controls for individual characteristics such as age, age square, gender, educational level and income as well as GSS round fixed effects. Notes: (i) The question on the mean level of political corruption (as perceived by individuals)comes from the WVS and is captured by the question "How widespread do you think bribe taking and corruption is in this country?". The variable is ranked from 1 to 4 with 1 denoting "Almost no officials involved in it" and 4 denoting "Almost all public officials are involved in it". The analysis uses the mean level for each country of origin; (ii) the question that is related to the attitudes of migrants towards corruption is "It is wrong to cheat on taxes". The variable takes values from 1 to 4 with 1 denoting "seriously wrong" and 4 denoting "not wrong"; (iii) robust standard error estimates, clustered at the country dimension, are reported in parentheses; (iv) *** denotes statistical significance at the 1 percent level, ${ }^{* *}$ at the 5 percent level, and ${ }^{*}$ at the 10 percent level, all for two-sided hypothesis tests. 


\section{Summary and Conclusions}

Motivated by the ongoing "Greek economic tragedy," which we partly view as the outcome of strategic complementarities in corrupt actions among different societal groups, we analyzed the issues of political corruption and tax evasion in the context of a simple economy with a publicly provided good. We showed that strategic complementarities may arise among agents, which lead to the existence of two stable equilibria. One of these equilibria is characterized by high rates of corruption and tax evasion and a low level of the public good, while the other equilibrium exhibits low rates of corruption and tax evasion and a high level of public good provision. These results are robust to various extensions of the basic model.

Naturally, we made a number of simplifying assumptions in order to keep the model analytically tractable. For example, we assumed homogeneity among all agents, which resulted in all of them being tax evaders. At the expense of simplicity, one could assume that there is a continuum of agents, who differ with respect to, for example, the transaction cost parameter of tax evasion. In such a case, the equilibrium tax evasion rate differs among agents. Nevertheless, the social interactions and the emergence of strategic complementarity, which is one of our main points, will still be present. Also, the assumption of a single politician bears little importance, as long as they act as a "group" and they realize the consequences of their actions on the provision of the public good. Finally, we assumed that an amount of the single public good occurred "naturally", or without government provision. We view this as a realistic assumption, since, as it is widely accepted, young people learn not only through formal education, but also through social interactions. More importantly, however, as we showed in the Appendix, our results hold even if we dispense with this assumption, as long as some of the amount raised from fines on tax evaders is spent on education and is not wasted.

We also provided empirical support for the main aforementioned result. More specifically, using data from the World Values Survey, we established empirically a correlation between attitudes towards tax evasion and perceived political corruption. Moreover, the

immigrant analysis based on the General Social Survey showed that this is not a spurious correlation or a result driven by endogeneity.

Our paper went beyond the simple establishment of multiple equilibria. It investigated the ability of different policies to eliminate the multiplicity and resolve the coordination 
failure. To this extent, we showed first that standard deterrence policies, i.e., changes in the probabilities of being caught or in the penalty rates, are not able to eliminate the multiplicity of equilibria. Next, we analyzed the issue of social coordination in the presence of a moral cost imposed on law-breaking agents. We demonstrated that such a cost, if strong enough, can lead to a unique equilibrium. Of course, this result is also consistent with a variety of similar approaches that go beyond enforcement to incorporate trust and other similar notions, e.g., intrinsic motivation, tax morale, slippery slope, deference versus defiance, etc. We used the concept of "stigma" to illustrate our point that the establishment of strong moral values is a necessary supplement to deterrence policies.

Finally, our result on the importance of social values accords well with the argument advanced in the literature regarding "trust" as one of three paradigms for government administrative policies (see Alm 2012). ${ }^{29}$ Accordingly, individuals are more likely to respond either to enforcement or services if they believe that the tax administration is honest; that is, "trust" in the authorities can have a positive impact on compliance. Nevertheless, we think that in practice the establishment of such a trust in societies with a high level of corruption is extremely difficult. Hence, these results can explain the persistence of corruption and tax evasion and the difficulty that often honest leaders face when trying to eradicate them.

\footnotetext{
${ }^{29}$ The other two paradigms are: a) an "enforcement" paradigm, where the emphasis is on the control of illegal behavior through frequent audits and excessively high fines, and b) a "service" paradigm, in which the tax administration acts as a facilitator and as a provider of services to taxpayers (see Alm 2012).
} 


\section{References}

[1] Alesina, A. and Giuliano, P., 2010. The power of the family, Journal of Economic Growth 15, 93-125.

[2] Allingham M. G. and Sandmo, A., 1972. Income tax evasion: A theoretical analysis. Journal of Public Economics 1, 323-338.

[3] Alm, J., 2012. Measuring, explaining, and controlling tax evasion: Lessons from theory, experiments, and field studies. International Tax and Public Finance 19, 5477 .

[4] Alm, J., McClelland, G. H. and Schulze, W. D., 1992. Why do people pay taxes? Journal of Public Economics 48, 21-38.

[5] Alm J., Sanchez I. and De Juan, A., 1995. Economic and noneconomic factors in tax compliance, Kyklos 48, 3-18.

[6] Alm, J. and Torgler, B., 2006. Culture differences and tax morale in the United States and in Europe, Journal of Economic Psychology 27, 224-246.

[7] Alm J., and Torgler, B., 2011. Do ethics matter? Tax Compliance and Morality, Journal of Business Ethics 101, 635-651.

[8] Alm J., Bloomquist, K. M., and McKee, M., 2013. When you know your neighbor pays taxes: Information, peer effects, and tax compliance," Working Papers 13-22, Department of Economics, Appalachian State University.

[9] Andreoni, J., Erard, and Feinstein, B. J., 1998. Tax compliance. Journal of Economic Literature 36, 818-860.

[10] Andvig, J. C. and Moene, K. O., 1990. How corruption may corrupt. Journal of Economic Behavior and Organization 13, 63-76.

[11] Barreto P. A. and Alm, J., 2003. Corruption, optimal taxation and growth. Public Finance Review 3, 207-240.

[12] Bénabou R. and Tirole, J., 2003. Intrinsic and extrinsic motivation, Review of Economic Studies 70, 489-520.

[13] Bentzen, J. S. (2013). Origins of religiousness: The role of natural disasters. Working Paper.

[14] Besley, T. and Coate, S., 1992. Understanding welfare stigma: Taxpayer resentment and statistical discrimination. Journal of Public Economics 48, 165-183.

[15] Ceroni, C. B., 2001. Poverty traps and human capital accumulation. Economica 68, 203-219.

[16] Chen, B. L., 2003. Tax evasion in a model of endogenous growth. Review of Economic Dynamics 6, 381-403.

[17] Cooper, R., and John, A., 1998. Coordinating coordination failures in Keynesian models. Quarterly Journal of Economics 103, 441-464. 
[18] Cowell, F. A., 1990. Cheating the Government. Cambridge, MA, MIT Press.

[19] De Gregorio, J. and Kim, S., 2000. Credit markets with differences in abilities: Education, distribution, and growth. International Economic Review 41, 579-607.

[20] Fernandez, R. and Fogli, A., 2009. Culture: An empirical investigation of beliefs, work, and fertility, American Economic Journal: Macroeconomics 1, 146-177.

[21] Giuliano, P., 2007. Living arrangements in western Europe: Does cultural origin matter? Journal of the European Economic Association 5, 927-952.

[22] Glomm, G., 1997. Parental choice of human capital investment. Journal of Development Economics 53, 99-114.

[23] Guiso, L., Sapienza, P. and Zingales, L., 2006. Does culture affect economic outcomes? Journal of Economic Perspectives 20, 23-48.

[24] Gordon, J. P. F., 1989. Individual morality and reputation costs as deterrence to tax evasion. European Economic Review 33, 797-805.

[25] Graetz, M. J. and. Wilde, L. L., 1985. The Economics of tax compliance: facts and fantasy. National Tax Journal 38, 355-363.

[26] Gray, C., 1999. United States practices in estimating and publicizing tax evasion. Discussion Paper Number 15, Harvard Institute for International Development.

[27] Haque, N. and Sahay, R., 1996. Do government wage cuts close budget deficits? A conceptual framework for developing countries and transition economies. IMF Working Paper 96/19.

[28] Kim, Y., 2003. Income distribution and equilibrium multiplicity in a stigma based model of tax evasion. Journal of Public Economics 87, 1591-1616.

[29] Litina, A., Moriconi, S. and Zanaj, S., 2014. The cultural transmission of environmental preferences: Evidence from international migration, Working Paper, University of Luxembourg.

[30] Litina, A. and Palivos T., 2013. Corruption and tax evasion: Reflections on Greek tragedy, Working Paper, University of Luxeburg and Bank of Greece.

[31] Lenter, D., Shackelford, D. and Slemrod, J, 2003. Public disclosure of corporate tax return information: Accounting, economics, and legal perspectives. National Tax Journal 56, 803-830.

[32] Luttmer, E. F. P. and Singhal, M. (2011). Culture, context, and the taste for redistribution, American Economic Journal: Economic Policy 3, 157-179.

[33] Mauro, P., 1995. Corruption and growth. Quarterly Journal of Economics 110, 681712 .

[34] Mauro, P., 1998. Corruption and the composition of government expenditure. Journal of Public Economics 69, 263-279.

[35] McCaffery, E. and Slemrod, J. (eds.), 2004. Behavioral Public Finance: Toward a New Agenda. Russell, Sage Foundation. 
[36] Moffit, R., 1983. An economic model of welfare stigma. American Economic Review 75, 1023-1035.

[37] Moutos, T. and Tsitsikas, C., 2010. Whither public interest: The case of Greece's public finances. FinanzArchiv: Public Finance Analysis 66, 170-206.

[38] Palivos, T. and Varvarigos, D., 2010. Education and growth: A Simple Model with Complicated Dynamics, International Journal of Economic Theory 6, 367-384.

[39] Palivos, T. and Varvarigos, D., 2013. Intergenerational complementarities in education, endogenous public policy and the relation between growth and volatility. Journal of Public Economic Theory 15, 249-272.

[40] Pyle, D. J.,1989. Tax Evasion and the Black Economy. The Macmillan Press, London.

[41] Sandmo, A., 2005. The theory of tax evasion: A retrospective view. National Tax Journal 58, 643-663.

[42] Skinner, J. and Slemrod, J., 1985. An economic perspective on tax evasion. National Tax Journal 38, 345-353.

[43] Spence, J., 1991. The Search for Modern China. WW Norton \&Company.

[44] Tanzi, V. and Shome, P., 1994. A primer on tax evasion. Bulletin for International Fiscal Documentation 48, 328-337.

[45] Tanzi, V. and Davoodi, H., 1997. Corruption, public investment, and growth. IMF Working Paper.

[46] Thomas, J. J., 1992. Informal Economic Activity. LSE Handbooks in Economics, London: Harvester Wheatsheaf.

[47] Torgler, B., 2004. Moral suasion: An alternative tax policy strategy? Evidence from a controlled field experiment in Switzerland. Economics of Governance, 5, 235-253.

[48] Vives, X., 2005. Complementarities and games: New developments. Journal of Economic Literature 43, 437-479.

[49] Yitzhaki, S., 1974. A note on income tax evasion: A theoretical analysis. Journal of Public Economics 3, 201-202. 


\section{Appendix}

\section{(This Appendix is not intended for publication)}

In Section A we present the proofs of the propositions and the corollary (Subsection A.1) as well as some extensions of our model (Subsection A.2). In Section B we explain in detail the definitions of the variables that we used in our empirical analysis and state our sources.

\section{A Proofs and Extensions}

\section{A.1 Proofs of Propositions and the Corollary}

\section{Proof of Proposition 1}

We must establish the existence of a pair $\left(z_{t}, \mu_{t}\right)$ that satisfies equations (6) and (9) simultaneously, after $\bar{z}=z$ is imposed in (9). For an arbitrary time period $t$, let $z_{t}=f\left(\mu_{t}\right)$ denote the solution to each citizen's problem, as described by equation (6); for each value of the embezzlement rate $\mu_{t}$ there exists a unique value of the evasion rate $z_{t}$. Similarly, let $\mu_{t}=g\left(z_{t}\right)$ denote the solution to the politician's problem, as described by equation (9). Note that both of these functions are continuous (see equations (6) and (9)). Thus, the composite function $g \circ f$ from $[0,1]$ to $[0,1]$ is continuous and, by Brower's fixed point theorem, has a fixed point.

\section{Proof of Proposition 2}

a) If $v=0$, then simple substitution in equation (9) shows that the politician's optimal response is independent of the citizens' actions. More specifically, $\mu_{t}=\beta /[\phi(1+\beta)]$. Substituting this value in (6), yields $z_{t}=1-[\phi(1+\beta) / 2 \beta s]$. b) Similarly, if $s=0$, then each citizen's best response is independent of the politician's action. Indeed, substituting $s=0$, equation (6) yields $z_{t}=0$. The equilibrium value of $\mu_{t}=0$ follows then from equation (9). c) If $v \geq \beta A \tau$, then the politician's best response function coincides with the side of the unit square that lies on the vertical axis (see Figure 1, where the best response functions are indicated by bold lines). The only common point then with the citizens' best response function is $(0,0)$. Similarly, if $\tau \geq 2 s$ then the citizens' best response function coincides with the side of the unit square that lies on the horizontal axis. Hence, the only common point with the politician's best response is $(0,0)$.

\section{Proof of Proposition 3}

a) The proof follows immediately from equations (6) and (9). b) Notice that if $v>0$, then the point $(0,0)$ satisfies both equations (6) and (9). c) The proof follows immediately from Figure 2 and equations (6) and (9). 


\section{Proof of Proposition 4}

The results follow directly after differentiating (6) and (9).

\section{Proof of Corollary 1}

It follows trivially from Proposition 3(b), where it is shown that if $v>0$ then $(0,0)$ is always an equilibrium.

\section{Results Regarding the Case of Stigma}

\section{Citizens}

Maximizing (14) subject to (5) and the non-negativity constraints, $c_{c} \geqslant 0$ and $1 \geqslant z \geqslant$ 0 , taking $\mu_{t}, E_{t}$ and $H_{t}$ as given, yields that the part of the best response function that lies strictly between zero and one is given by the positive root of the following quadratic equation in $z$

$$
2 s \phi \tau A \mu^{2} z^{2}+\left(\phi \tau^{2} A-2 s \phi \tau A \mu+2 s v\right) \mu z+\tau v-2 s v \mu-\gamma \tau=0 .
$$

Tedious calculations show that if

$$
\gamma<\frac{(\phi \tau A)^{2}\left(2 s \mu-\tau^{2}\right)+4 s v\left(\phi \tau^{2} A-\phi s v \tau A \mu-s v\right)}{8 \phi s \tau^{2} A}
$$

the politician's action is unambiguously a strategic complement for the citizens, i.e., $d z / d \mu>0$.

\section{A.2 Extensions of the Model}

\section{An Alternative Punishment Scheme for the Politician}

In this subsection we analyze an alternative punishment scheme for the politician, namely, if the politician is caught to have peculated public funds, then he is thrown out of office and receives zero consumption. More specifically, the utility function of the politician is now

$$
(1-q)\left(c_{p t} h_{t+1}\right)
$$

where $c_{p}$ is given by (8). Maximizing (A.2) subject to (8), (1), (3) and the non-negativity constraints, $c_{p} \geqslant 0$ and $1 \geqslant \mu \geqslant 0$, taking $\overline{z_{t}}$ and $H_{t}$ as given, leads to the same best response function as in the benchmark model (equation 9). Moreover, each citizen's problem is the same as the one analyzed in Section 3 and hence her best response function is again given by equation (12).

Obviously, the results in this case are very similar to the ones obtained in the benchmark model as well as in the model with fines (Section 3). For a wide range of parameter values there exist three equilibria. Moreover, if $v>0$, then changes in the policy parameters, e.g., $p, q, \tau$, and $\phi$, cannot eliminate the high corruption equilibrium. 


\section{Revenue from Fines are Allocated to the Public Good}

In the main text we assume that the revenue from fines on tax dodgers and the politician is neutralized. Next, we analyze the case where this revenue is used to finance public education. Accordingly, equation (3), which gives the level of spending on public education, changes to

$$
E_{t}=\mu_{t} \phi N \tau \overline{z_{t}} H_{t}+p \tau\left(1-\overline{z_{t}}\right) N H_{t}+q\left(1-\mu_{t}\right) \phi N \tau \overline{z_{t}} H_{t}
$$

where $p \tau\left(1-\overline{z_{t}}\right) N H_{t}$ and $q\left(1-\mu_{t}\right) \phi N \tau \overline{z_{t}} H_{t}$ represent the expected revenue from fines imposed on tax evaders and the politician, respectively.

Each citizen's problem does not change and her best response is again given by equation (12). Following the same steps as in Section 3, we find the politician's best response to be

$$
\mu_{t}=g\left(\bar{z}_{t}\right)=\left\{\begin{array}{ccc}
0 & \text { if } & \tau N A \bar{z}(1+p-2 \phi q) \leq v+\tau p N A \\
\frac{N A \tau\left[\bar{z}_{t}(1+p)-p-2 \phi q \bar{z}\right]-v}{2 A \phi \bar{z}_{t}(1-q)} & \text { if } & \tau N A \bar{z}(1+p-2 \phi)<v+\tau p N A<\tau N A \bar{z}(1+p-2 \phi q) \\
1 & \text { if } & v+\tau p N A \leq \tau N A \bar{z}(1+p-2 \phi) .
\end{array}\right.
$$

Simple differentiation shows that $d \mu_{t} / d z_{t}$ is positive and hence private citizens' action is a strategic complement for the politician. Once again, for a wide range of parameter values there exist three equilibria, one corner and two interior or one interior and two corner. These equilibria have the same stability properties as in the benchmark model, namely the lowest (high tax evasion and high corruption) and the highest (low tax evasion and low corruption) equilibria are stable, whereas the intermediate equilibrium is unstable.

Note however that, in contrast to the other versions of the model, in this case strategic complementarity and multiple equilibria can arise even if $v$, the rate of human capital transferred freely to the next generation, is zero. The reason behind this result is that, even if $z_{t}$ or $\mu_{t}$ is zero, there will still be some acquisition of human capital financed by the fines on tax evaders and corrupt politicians. As before, there does not exist a policy that can eliminate multiplicity. More specifically, since the point $(0,0)$ satisfies both equations (12) and (A.4), changes in the policy parameters, e.g., $p, q, \tau$, and $\phi$, cannot eliminate the high corruption equilibrium.

\section{Endogenous Probabilities}

In our last extension, we attempt to endogenize the probabilities that agents face. More specifically, we assume that citizens choose the percentage of their income that they report to the tax authorities and face a probability of being audited equal to $q_{c t}$. If audited, their true income is revealed and they pay a penalty $\pi$ on evaded income tax. The politician, on the other hand, peculates an amount $\mu_{t}$ of the tax revenue earmarked for public education. 
Nevertheless, there is a technical relation $q_{p t}=\alpha \mu_{t}$ between the embezzlement rate and the probability to be caught, i.e., the more the politician peculates, the more likely he will get caught; $\alpha \in(0,1)$ is an institutional parameter (see Allingham and Sandmo, 1972). For simplicity, we assume, that if the politician gets caught having peculated funds, then he is thrown out office and consumes nothing. Moreover, in equilibrium $q_{c}=q_{p t}=q$, that is, the probability of being caught is the same for all agents, or the law is applied equally to all. ${ }^{30}$ The human capital accumulation and the expenditure on public education are still given by (1) and (3).

Citizens face essentially the same problem as in Section 3 and their best response function is

$$
z_{t}=f\left(q_{t}\right)=\left\{\begin{array}{ccc}
0 & \text { if } \quad \tau \geq \frac{2 s q_{t}}{\alpha\left(1-q_{t} \pi\right)} \\
1-\frac{\alpha(1-q \pi) \tau}{2 s q_{t}} & \text { if } \quad \tau<\frac{2 s q_{t}}{\alpha\left(1-q_{t} \pi\right)} .
\end{array}\right.
$$

Simple differentiation yields $d z_{t} / d q_{t}>0$.

The politician's problem can be represented as one where he chooses $c_{p t}$ and $q_{p t}$ to maximize

$$
\max _{c_{p t}, q_{p t}}\left(1-q_{p t}\right)\left(c_{p t} h_{t+1}\right)
$$

subject to (8), the non-negativity constraints, and equations (1) and (3), taking $\bar{z}_{t}$ and $H_{t}$ as given. This leads to the following best response function

$$
q_{t}=\left\{\begin{array}{cll}
0 & \text { if } & \bar{z}_{t} \leq \frac{v(\alpha+\phi)}{\tau N A \phi} \\
g\left(\bar{z}_{t}\right) & \text { if } & \frac{v(\alpha+\phi)}{\tau N A \phi}<\bar{z}_{t}
\end{array}\right.
$$

where

$$
\bar{z}_{t}=g^{-1}\left(q_{t}\right)=\frac{\alpha v}{\tau N A \phi} \frac{\alpha-2 q \phi+\phi}{3 q^{2} \phi-2 q(\alpha+\phi)+\alpha} .
$$

For a wide range of parameter values there exist three equilibria, the origin and two internal. For example if $A \times N=2, \tau=0.4, \alpha=s=0.9, v=0.04, \phi=0.7, \pi=1.01$, then the three equilibria $(q, z)$ are $(0,0),(0.184,0.113)$ and $(0.337,0.609)$. Importantly, changes in $\pi, \tau$, and $\phi$ cannot eliminate the multiplicity of equilibria.

This extension is more interesting since it endogenizes policy and answers the question concerning who will enforce policy and for what reason. Evidently the presence of

\footnotetext{
${ }^{30}$ This is a simplifying assumption since the politicians are the ones choosing the auditing probabilities in the economy. The aim of this assumption is to highlight that even in the case of endogenous auditing probabilities multiplicity of equilibria cannot be eliminated. Alternatively, we could assume that the politician chooses different auditing probabilities for himself and for the citizens without qualitatively changing our results. We believe though that it is not an implausible assumption, since in most democratic societies laws are equally applicable to anyone.
} 
strategic interactions and the "fear" that citizens will respond to politicians' embezzlement with higher evasion is a sufficient reason to enforce positive auditing probabilities However, as was the case in the benchmark model, not even endogenous policy can eliminate multiple equilibria since it does not resolve the problem that arises due to strategic complementarity.

\section{B Variable Definitions and Sources}

\section{B.1 World Values Survey}

\section{Outcome Variables}

Tax Evasion. The question related to tax evasion is "Please tell me for each of the following statements whether you think it can always be justified, never be justified, or something in between, using this card: Justifiable to cheat on taxes". The variable is ranked from 1 to 10 with 1 denoting "Never justifiable" and 10 denoting "Always justifiable".

\section{Controls}

Political Corruption. The question on the extent of political corruption (as perceived by individuals) is captured by the question "How widespread do you think bribe taking and corruption is in this country?" The variable is ranked from 1 to 4 with 1 denoting "Almost no officials involved in it" and 4 denoting "Almost all public officials are involved in it".

Age. The age of the respondent. The age is taken from the four waves (1981-2002) of the WVS sample.

Gender. The gender of the respondent. The gender is taken from the four waves (1981-2002) of the WVS sample.

Income. The variables captures the income of individuals and is divided in 10 categories with 1 denoting "Lower Step" and 10 denoting "Tenth Step".

Level of Education. The highest level of education attained by the respondent. The questionnaire distinguishes seven different levels of education (inadequately completed elementary education, completed (compulsory) elementary education, (compulsory) elementary education and basic vocational qualification, secondary, intermediate vocational qualification, secondary, intermediate general qualification, full secondary, maturity level certificate, higher education lower-level tertiary certificate, higher education - upper-level tertiary certificate). The data are taken from the four waves (1981-2002) of the WVS sample.

\section{B.2 General Social Survey}

\section{Outcome Variables}

Tax Evasion. The question that is related to the attitudes of migrants towards corruption is "It is wrong to cheat on taxes". The variable takes values from 1 to 4 with 1 denoting "seriously 
wrong" and 4 denoting "not wrong".

\section{Controls}

Political Corruption. The question on the extent of political corruption (as perceived by individuals) comes from the WVS and is captured by the question "How widespread do you think bribe taking and corruption is in this country?" The variable is ranked from 1 to 4 with 1 denoting "Almost no officials involved in it" and 4 denoting "Almost all public officials are involved in it". The variable is calculated as the mean value for each country.

Age. The variable indicates the age of individuals and takes values between 18-89. Age squared is the squared value of Age.

Education. The variable on individuals' education is an ordered variable taking values from 0 to 20, denoting the highest number of years in school.

Ethnic Origin. The variable captures the ethnic origin of the family of individuals. They can declare up to three countries of origin ordering them according to which they relate to more. In the analysis we choose their first response. The respondents come from 23 countries or continents: Austria, Belgium, Canada, China, Czech Republic, Denmark, Finland, France, Germany, Greece, Hungary, India, Ireland, Italy, Japan, Lithuania, Mexico, the Netherlands, Norway, Philippines, Poland, Portugal, Puerto Rico, Russia, Spain, Sweden, Switzerland, Great Britain and Yugoslavia. Moreover Africa and the Arabic countries are part of the sample, denoting the sum of all migrants of African and Arabic origin, respectively.

Gender. The variable takes the value 1 if the gender of the individual is male.

Income. The variables captures the income of individuals. It has 12 categories: $1000 \$, 1000 \$-$ $2999 \$, 3000 \$-3999 \$, 4000 \$-4999 \$, 5000 \$-5999 \$, 6000 \$-6999 \$, 7000 \$-7999 \$, 8000 \$-9999 \$, 10000 \$-$ $14999 \$, 15000 \$-19999 \$, 20000 \$-24999 \$, 25000 \$$ or more.

Parents Born in the US. The question on parents' origin is ranked as follows: 0 if both parents of the migrant are born in the US, 1 if only the mother was born in the US and 2 if only the migrant's father was born in the US.

Grandparents Born in the US. The variable on the origin of grandparents takes the value 0 if all grandparents were born in the US, the value 1 if at least one was born outside the US, 2 if two were born outside the US, 3 if three were born outside the US and 4 if all four grandparents were born outside the US. 